\title{
Reconstruction and Presentation of Reality on Television: An Analytical Study of Kannada Channels
}

Rajeshwari $R^{*}$

\section{Abstract}

Television has altered the way news is constructed and delivered. Due to competition and TRP, television news channels are experimenting with different techniques to attract attention and reach audiences. Reconstruction with the help of graphics and animation along with docudramas has become quite common in various kinds of television programs. From hard to soft news storytelling television channels have adopted different patterns of visual construction to make an emotional appeal to the audience. Media theories have established the power of visual media in the common man's life. The present study focuses on the trend related to visual reconstruction of reality in storytelling among Kannada channels. This qualitative study specifically evaluates the various techniques of visual construction, reasons for visual construction, program patterns which use these practices significantly and investigates the influence of visual construction in storytelling. The content of Kannada television programs is evaluated in order to gather primary data. The programs that use visual construction regularly and news items which depend on visual construction have been selected for analysis.

Keywords: Visual construction, Television, Storytelling, Reach audience

* Bangalore University, Bengaluru, India; rajeshwari.rnayak@gmail.com 


\section{Introduction}

We live in a mass mediated society. News on television, which takes a major part in the ratings, is said to be the most real and least mediated of programs on TV. Like other programs, news also has a similar need to attract the attention of viewers - to inform and entertain. In order to reconstruct the story, TV channels use library footage, graphics and animation which 'authenticate' stories.

At one level, television news producers construct a reality through the decisions made about coverage of events and their placement within a newscast. At another level, viewers construct their own realities by interpreting news through a set of personal experiences. The act of making news is the act of constructing reality itself rather than a picture of reality (Touch man, 1978).

As Weimann (2000) observes, journalism is mostly storytelling. With the advent of television, people are experiencing history alongside the present scenario. When people watch television they communicate with the world, with their past, present and future.

\subsection{Background of the study}

Today the media world is characterized by the rapid growth of technology to an unpredicted extent. One can create or reconstruct anything with the help of technology. This enables viewers to understand the story easily.

Television is making use of this technology to the maximum extent. Graphics and animation are inevitable for every type of television program today. To satisfy the needs of the viewer and to beat the competition from other media, television channels are reconstructing their content with different elements.

\section{Review of Literature}

Electronic media has strengthened the power of the media with regard to reconstruction of reality. Television continues the present and diffuses reconstruction of reality rather than accurate representations. The impact in shaping audience perceptions is, in the age of television, more powerful than ever (Weimann, 2000). 
Television is a centralized system of storytelling. It is part-andparcel of our daily lives. Its drama, commercials, news and other programs bring a relatively coherent world of common images into every home. Television cultivates from infancy the predispositions and preferences that used to be acquired from other primary sources (Gerbner, Gross, Morgan, \& Signorielli, 1986).

The power of media lies not only (and not even primarily) in its power to declare things to be true but in its power to determine the form in which the declaration appears. News in a newspaper or on television has a relationship to with the "real world", not only in terms of content but in form. In this manner, the world is incorporated into unquestionable and unnoticed conventions of narration and then transfigured, no longer for discussion, but rather as a premise of any convention at all (Schudson, 1982).

As Nimmo and Combs (1983) observe in their study, "media of communication intervene media in the form of language, customs, symbols, stories, and so forth. That very intervention is a process that creates and re-creates (constructs and reconstructs) our reality of the moment and over the proverbial long haul" (cited by Liu, N.X).

Television news viewers make future-viewing decisions based on how well their needs were gratified (Palmgreen, Wenner \& Rosengren, 1985). Local news, like other forms of news, is driven by the need for larger audiences. Issues that attract attention, generate compelling visual images and fit the fast-paced nature of broadcast news are especially likely to attract coverage (Iyengar, 1997).

In an era of infotainment, edutainment and also militainment of real life soaps, docudramas, faction journalism and extreme TV of gender-swapping and avatars, it would appear that an empirical constructivism which considers constructivity to be a trend toward greater fictionalization, is more necessary than ever (Weber, S. 2002). Dramatic changes in the technology of reproduction have led to the implosion of representation and reality (Baudrillard, 1988).

\subsection{Theoretical framework}

Uses and gratifications theory looks at what people do with media and how they use media to gratify their needs. A medium is used 
more when the existing motives to use the medium lead to increased satisfaction. Audiences use media to fulfill their psychological, physiological and social needs. The choices that people make are motivated by a desire to satisfy (or 'gratify') a range of needs. Denis McQuail lists four uses for mass media; Surveillance, Personal identity, Personal relationships and Diversion.

Cultivation theory states that heavy exposure to mass media, namely television, creates and cultivates attitudes more consistent with a media-conjured version of reality than with actual reality. Gerbner views this television world as "not a window on or reflection of the world, but a world in itself". This created version of the world entices heavy viewers to make assumptions about violence, people, places and other fictionalized events, which do not hold true to real life events. The effect of massive television exposure by viewers over time subtly shapes the perception of social reality for individuals and, ultimately, for our culture as a whole.

Priming theory refers to enhancing the effects of the media by offering the audience a prior context - a context that will then be used to interpret subsequent communication. The media serves to provide the audience with standards and frames of reference. It has primed the audience regarding what a news program looks like, what a credible person looks like, etc.

By priming audiences with particular images or semantics prior to a persuasive message, a communicator can actually heighten the likelihood that thoughts with much the same meaning as the stimulus will come to mind.

A frame theory refers to the way media and media gatekeepers organize and present the events and issues that they cover and the way the audiences interpret the information they are provided with. Media products are human products, constructs that the audience takes for granted. Frames are abstract notions that serve to organize or structure social meanings. Frames influence perceptions of the news among the audience. This form of agendasetting not only tells people what to think about but also how to think about it. 
Framing leads people to accept one meaning over another. It is a skill that has a profound impact on how organizational members understand and respond to the world in which they live. It is a skill that most successful leaders possess yet one that is not often taught.

\subsection{Scope of the study}

The present study would contribute to the trends in visual media and the scope for visual re-construction along with its related advantages. In the present scenario, television uses visual construction frequently in programs such as news bulletins, crime shows, religious and scoop stories. It has become an essential part of storytelling in visual media, for the purpose of attracting larger audiences and retaining TRPs.

The study would also help to understand the trends of visual reconstruction in storytelling as seen in Kannada channels. Further, it would guide other media professionals in story reconstruction and its advantages. It would also aid social scientists and media educators in their attempt track the development of visual reconstruction in Kannada television channels.

\section{Objectives}

The general objective of this research is to detect and map the trends among Kannada channels related to visual reconstruction of reality in storytelling. The study specifically evaluates the various techniques of visual construction, reasons for visual construction, program patterns which use these practices to a significant extent and finally, to investigate the influence of visual construction in storytelling.

\section{Methodology}

The study is qualitative in nature. Kannada television program content has been evaluated to gather primary data. Programs of different Kannada TV channels have been selected for the analysis. The special programs which use visual reconstruction regularly and news items which depend on visual construction are analyzed. 
Programs such as crime, supernatural mysteries, religious programs and some special segments of channels have been selected based on popularity. These programs were observed and conclusions drawn based on the set objectives.

\subsection{Analysis}

Almost all Kannada channels create their programs using visual reconstruction to persuade viewers to watch it. News channels largely depend on this technique.

\subsection{Kannada TV Programs with Visual Reconstruction}

Program patterns using visual construction significantly in Kannada channels include crime-related programs such as Warrant, FIR, Crime station, Crime story; Supernatural mystery programs like Heegu Unte, Ella Mayavo, Idu Saadya, Health science and technology programs which demonstrates complicated issues; prime time news and; other special programs.

These programs reconstruct their stories with different visual techniques. Post-presentation of an event generally uses the method of visual reconstruction to represent it for various reasons.

\section{Trends and Techniques of Visual Reconstruction}

Some techniques of visual construction are graphics, animation, illustrations, docudrama, extraction of video from films and other entertainment programs, short programs capturing various emotions of different personalities, reenactments etc. These techniques are repeatedly used by Kannada television channels in their programs.

Supernatural mystery programs present extraordinary freedom for the reconstruction of visuals. Here, visuals are produced through enactment or they make use of animations, illustrations and docudramas.

Crime related programs depend on extractions of video from other media such as film, tele-serials with graphics, illustrations, and reenactment. During accidents or crises, television channels mostly 
depend on visual reconstruction to represent the story, as these stories are reported only after they happen.

News is also presented with the support of graphics, illustrations and video extracts. The best examples of this are news on sexual harassment, molestation, political corruption cases and telephone conversations relayed during news presentations. Here, the television channels recreate the entire story for its viewers.

Television programs related to historical sequences and speculations of the future are also presented through visual reconstruction.

\subsection{Causes and Effects}

Why does television reconstruct visuals to present a story? There are many reasons behind this practice. Today, all media is trying hard to attract and retain their target audience. Television channels focus on TRP to obtain revenue for their survival. Now, viewers have the opportunity to select programs which cater to their specific needs and wants. In order to compete with each other, every television channel employs varied methods to achieve better content and presentation. Visual reconstruction is one way to attract the attention of the viewer towards a particular, as it is a medium that targets both literate and illiterate audience.

Television uses visual imagery for difficult-to-understand messages. As all audiences of television are unable to understand the messages, visual reconstruction assists them. Thus, visual reconstruction decodes the meaning of television messages.

While presenting a story through reconstruction, the viewer visualizes the entire situation as if he or she is physically present at the location of the event. Through reconstruction, media is able to convey lot of details in a short amount of time. Programs retell the story melodramatically to make the viewer enjoy the program as well as use it as a tool to inform viewers regarding the seriousness of a particular issue.

Visual impact on behavior, emotion and cognition is immense. It is common knowledge that when information is presented with the support of visual elements it reaches the viewers cognizance easily. When it reaches the cognition level of the viewer, the sender of the 
message achieves his/her mission of drawing attention towards the program.

Visual reconstruction in storytelling contributes to various aspects of media presentation. It reduces the risk of confusion among viewers as it unambiguously presents information with the support of visual reconstruction. It reflects and helps viewers understand reality as television through programming constructs and mediates reality to its viewers. When visual reconstruction appeals to the cognitive level of the viewer, they perceive messages and naturally follow the program with much interest. By gaining the viewer's consent, television channels maintain their TRP and retain a competitive edge against other channels.

\section{Conclusion}

People watch television to fulfill their needs of entertainment, infotainment and edutainment. They rely on particular channels when television satisfies their requirements. Today, viewers have more options than previously for the gratification of their specific prerequisites. Therefore, to attract and retain the attention of the viewer, television channels use the technique of visual reconstruction in storytelling. For the purpose of shaping perceptions, television channels are adopting visual reconstruction for the presentation of news stories. When television intends to frame expected meaning or the viewer's consent, the gate keepers in the media organizations attempt to accomplish that with visual reconstruction. Content analysis states that television is setting a trend in the use of visual reconstruction to tell a story. Different techniques such as graphics and animation, illustrations, docudrama, extraction of video from films and other entertainment programs are used to present the story coherently. Crime and supernatural mystery programs make significant use of visual reconstruction in storytelling. To persuade the viewer, compete for TRP and for greater clarity, visual reconstruction is used in television programs. It has also been found that programs that use visual reconstruction are more popular among viewers and accordingly have the highest TRPs. Consequently, television professionals can make better use of visual reconstruction in other general programs to reach their target audiences. 
Rajeshwari R Reconstruction and Presentation of Reality on Television

\section{References}

Baudrillard, J. (1988). Selected Writings, ed. Mark Poster. Stanford, Calif: Stanford University Press

Domke, D., Shah, D.V., \& Wackman, D.B. (1998). Media priming effects: accessibility, association, and activation. Communications abstracts, 21(6).

Gerbner, G., \& Gross, L. (1976). Living with television: The violence profile. Journal of Communication, 26, 172-199.

Gerbner, Gross, Morgan, \& Signorielli. (1986). Living with Television: The Dynamics of the Cultivation Process. Retrieved from http:/ / web.asc.upenn.edu/gerbner/Asset.aspx?assetID=1644 accessed on 27th January, 2017.

Iyengar, S. (1997), Is anyone responsible? How television frames political issues. Chicago: University of Chicago Press.

Palmgreen, P., Wenner A.L., \& Rosengren, K.E. (1985). Media gratification research: Current perspectives, Sage publications, Inc.

Retrieved from http://translationjournal.net/Featured-Article/newstranslation-as-reconstruction-of-reality-within-frames.html

Schudson, M. (1982). The Power of News. Massachusetts London, England: Harvard University Press Cambridge.

Weber, S. (2002). Media and the construction of reality. Retrieved from https://www.mediamanual.at/en/pdf/Weber_etrans.pdf on 29.01.2017.

Weimann, G. (2000). Communicating Unreality: Modern Media and the Reconstruction of the reality, New Delhi: Sage Publications, Inc. 